reviews the progress of bubble chamber development; this elegant technique has been developed into an instrument of great power for high-energy physies, and is entering the realm of heavy engineering with the 72-in. chamber at Berkeley, California. However, commensurate effort is needed, and is beginning to be applied, on the problem of evaluating the mass of visual data produced with the bubble chamber, if the necessary good statistics are to be obtained; Dodd's article does not review this problem. Brooks discusses the present state of knowledge of the mechanism of scintillation in organic materials, and reviews recent data on the properties of organic scintillatorsincluding liquid and plastic scintillators.

The authors have again maintained the high standard set by previous volumes in the series, and again they are all active workers in the fields which they discuss. As usual the quality of production is excellent, but this time there has been a longer delay in publication. The articles do not set out to be exhaustive, but are intended for specialists in related fields. The same characteristic is evident in the choice of topics in the whole series so far; no attempt is made to give frequent up-to-the-minute progress reports on all aspects of nuclear physics. In this way it has been possible to select topies in which a certain degree of stability has been reached, and the policy has been successful since the articles have not rapidly become out of date. However, rather few articles have so far been devoted to experiments in high-energy physies, in which much solid progress has been made during the past few years ; perhaps we may see one or more articles on this important subject in the next volume.

'T. G. Pickavance

\section{A COMMUNITY OF PENGUINS}

\section{A Population Study of Penguins}

By L. E. Richdale. Pp. iii $+\mathbf{1 9 5}+\mathbf{2}$ plates. (Oxford : Clarendon Press; London: Oxford University Press, 1957.) 42s. net.

7 HIS book is the record of part of a most careful and painstaking field research extending over nearly a score of years on the penguins of New Zealand. The studies described here mainly concern the yellow-eyed penguin, Megadyptes antipodes, a non-migratory species that is resident in the southeast of New Zealand and some of the adjacent islands ; the colonies situated on the Otago peninsula where the author worked lie at the extreme north of the breeding range. None of the breeding areas studied lies more than twenty miles from the city of Dunedin where the author lives, and consequently he was able to visit them 1,318 times in the course of his work.

The observations recorded and analysed in this research were made chiefly on just over 400 birds divided almost equally between the sexes, and the results of 819 separate matings during eighteen seasons are traced. "The history of the individual resident penguins was well known to me. Sometimes the acquaintance lasted only one season, after which the penguin disappeared, but five birds were still present in 1953-54, seventeen seasons after they were first found." Recognition of the birds, of course, meant that it was necessary to mark them ; "all adults and juveniles when first met were banded and footmarked, the latter device making it impossible to lose the identity of the bird should a band come off". But it is astonishing to read that when the author started his work in 1936 he was "unaware that wild birds were being banded in America and Europe", and that inquiries from "authorities in New Zealand" on how to band or mark wild birds led to nothing. 'The bands he eventually obtained from Europe were unsatisfactory and so, since the end of 1938 , he has made his own although it takes fifteen minutes to manufacture each one. Mr. Richdale analyses and discusses the results of his field work with equal patience and care, and presents the most complete account of the population dynamics that has yet appeared about any species of penguin.

The author found that there was considerable wandering during the first five years of the birds' lives, but after that the penguins rarely adopted. a new breeding place. Linked with this is the length of the pair-bond; there is a high rate of dissolution in youth, and in addition some older birds are unable to retain their mates because of incompatibility and the pressure of intra-sexual competition. "Once this period of instability is passed, 63 per cent of the pair-bonds on the average tend to remain intact in a succeeding season." It is not easy to sex living penguins, but one bird that was aecidentally killed was dissected and, "because Yellow-eyed Penguins change their mates frequently it was possible by means of this one known bird to trace accurately the sex of every penguin that lived in that particular breeding area in the research period, both before and after the death of the bird".

As a result of his work the author was able to assess the precise composition of a penguin community and the proportions of juveniles, non-breeders and breeders, with, in many cases, their blood-relationship to each other, and the sex-ratio. Among many other matters, he also discusses the influence of age and other factors on breeding success, and the survival and mortality rates of juveniles and adults. A valuable chapter gives a detailed account of the process of moulting and compares that of the yelloweyed penguin with what is known of the phenomenon in other species of penguin.

The book is produced according to the standards expected of the Press from which it comes and worthily presents an important contribution to ornithology. L. HaRRison MatThews

\section{SOIL IMPROVEMENT AND BETTER CROPS}

\section{Soil Fertility and Fertilizers}

By Samuel L. Tisdale and Werner L. Nelson. Pp. xxii +430 . (New York and London: The Macmillan Company, 1956.) 45s. net.

\section{Farm Soils}

Their Fertilization and Management. By Prof. Edmund L. Worthen and Prof. Samuel R. Aldrich. Fifth edition. (Wiley Farm Series.) Pp. viii $+439+$ 5 plates. (New York : John Wiley and Sons, Inc.; London: Chapman and Hall, Ltd., 1956.) 40s. net.

TTHE book by Tisdale and Nelson is essentially a product of North Carolina State College, which has a deservedly high reputation for its studies in plant nutrition and for its State advisory soil service. It is a presentation, for the student of soil fertility, of the fundamental principles of the subject, sup. 